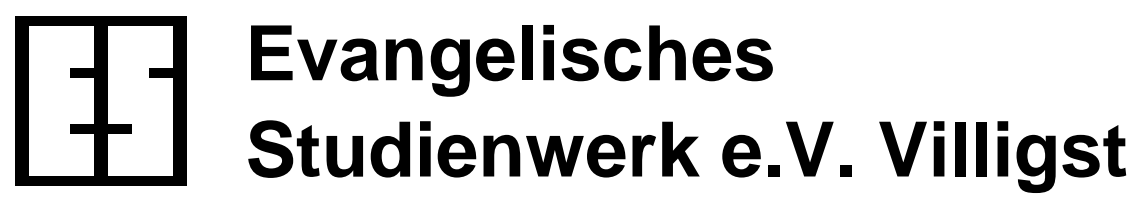
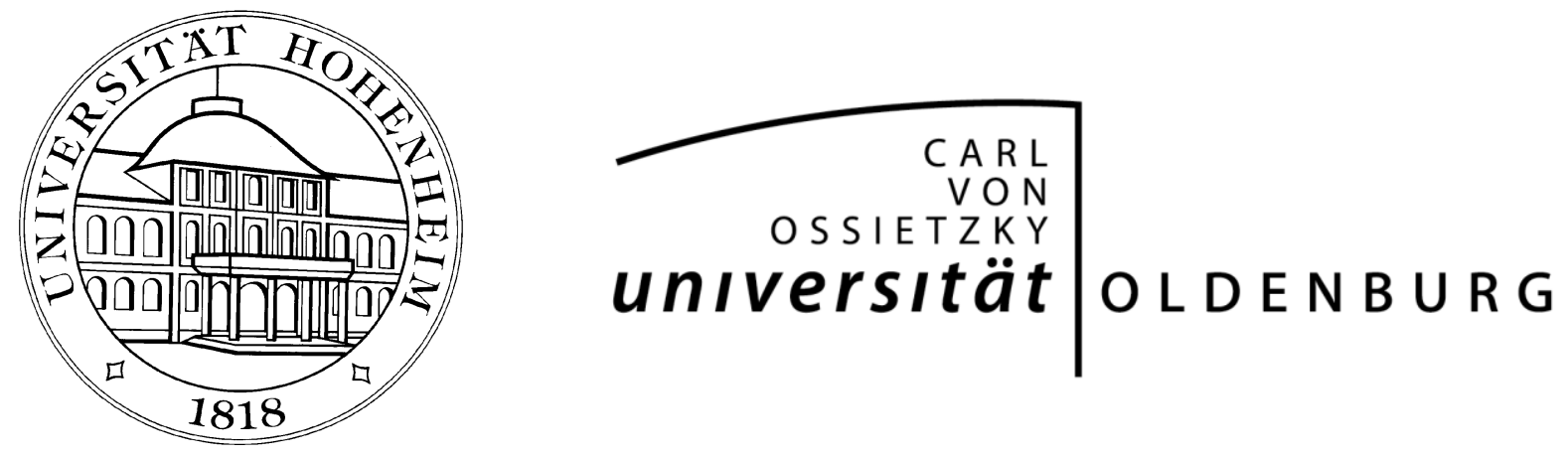

Schriftenreihe des Promotionsschwerpunkts

Globalisierung und Beschäftigung

Nr. 46/2015

Business Cycles in the Economy and in Economics: An Econometric Analysis

von

Niels Geiger und Vadim Kufenko

Stuttgart-Hohenheim

ISSN 1618-5358 
Unemployment is persistently high in many European countries. It is frequently attributed to 'functional deficiencies of labor markets', even though to a large extent caused by demand and supply shifts in goods markets and financial markets. The $\mathrm{PhD}$ program Globalization and Employment therefore focuses on the employment effects of structural change and macroeconomic developments and encourages research by granting scholarships. The dissertation projects address topics such as new technologies, processes of internationalization and system transformation, endogenous finance constraints and various strategies of fiscal and monetary policy.

Work and supervision in the $\mathrm{PhD}$ program follows the structures of a standard graduate school. Coordinators and editors of the discussion paper series are the following professors:

Prof. Dr. Harald Hagemann

Department of Economics (520H)

University of Hohenheim

D-70593 Stuttgart

Prof. Dr. Heinz-Peter Spahn

Department of Economics (520A)

University of Hohenheim

D-70593 Stuttgart

Prof. Dr. Hans-Michael Trautwein

Department of Economics and Statistics

Carl von Ossietzky University Oldenburg

D-26111 Oldenburg harald.hagemann@uni-hohenheim.de

peter.spahn@uni-hohenheim.de

michael.trautwein@uni-oldenburg.de

$\mathrm{PhD}$ projects in the program can be funded by grants of the Evangelisches Studienwerk e.V. Villigst. Application forms can be ordered from:

Evangelisches Studienwerk e.V.

Promotionsförderung

Iserlohner Str. 25

D-58239 Schwerte

Phone: +49 (2304) 755-215, Fax: +49 (2304) 755-250

For further information about the $\mathrm{PhD}$ program Globalization and Employment as well as the PDF-files of the discussion papers see:

http://www.globalization-and-employment.de 


\title{
Business Cycles in the Economy and in Economics: An Econometric Analysis
}

\author{
Niels Geiger and Vadim Kufenko* \\ University of Hohenheim, Department of Economics
}

\begin{abstract}
It is sometimes pointed out that economic research is prone to move in cycles and react to particular events such as crises and recessions. The present paper analyses this issue through a quantitative analysis by answering two closely related research questions: (1) whether or not there are patterns in the economic literature on business cycles, and (2) whether or not these are correlated with movements in actual economic activity. To tackle these questions, a bibliometric analysis of key terms related to business cycle and crises theory is performed. In a second step, these results are confronted with data on actual economic developments in order to investigate the question of whether or not the theoretical literature follows trends and developments in economic data. Respective time series are detrended by the Kalman filter in order to estimate cycles. To determine the connection between economic activity and developments in the academic literature, a descriptive analysis is scrutinized by Granger causality tests. The paper also includes IRF analysis for quantitative assessment of the effects from economic to bibliometric variables. The results point towards a confirmation of the hypothesis of an effect of business cycles and crises in economic variables on discussions in the literature.
\end{abstract}

Keywords: bibliometric analysis, business cycle theory, empirical analysis

JEL Classification: B10, B22, E32, E39

\footnotetext{
*University of Hohenheim, Department of Economics, Schloss Osthof-West. Niels.Geiger@unihohenheim.de and Vadim.Kufenko@uni-hohenheim,de; Tel.: +4971145923783; +4971145922562. Paper presented at the 19th Annual ESHET Conference, May 14-16 2015 in Rome. We thank our discussant, Pedro Garcia Duarte, for his substantial and constructive remarks. The authors are also grateful for comments by Harald Hagemann and Johannes Schwarzer on an earlier presentation of this paper.
} 


\section{Introduction}

In the literature on the history of economic thought, it is sometimes pointed out that not only does economic development go through business cycles, but that developments in theory may be of a cyclical nature, or at least contain some cyclical elements, as well (see e.g. Kurz 2006). Merging the two lines of thought together, i.e. thinking of a possible cyclicality in and of business cycle theory, immediately brings some intuitively appealing examples to mind: Keynes's General Theory (1936), e.g., was published shortly after the onset of the Great Depression and initiated increased interest in analysing business cycles from a new perspective and has, at least according to casual observations, experienced renewed interest over the past years of the 'Great Recession'. Indeed, numerous examples can be found in the literature which draw a causal link between economic crises, and the frequency of discussions of these and related events. However, so far, those discussions have been unsystematic, casual, and almost exclusively without any actual quantitative reference. The present paper aims to fill this gap by quantitatively and econometrically answering two closely related research questions: (1) whether or not there are particular patterns, especially of a cyclical kind, in the economic literature on business cycles, and (2) whether or not these are in any way correlated with movements and changes in actual economic activity.

To tackle the first question, a bibliometric analysis (resembling the method used in Geiger 2014) of key terms related to business cycle and crises theory in economics papers archived in JSTOR is performed. The results are long time series which are set into a historical context of seminal contributions. This allows for a discussion of the question of whether or not the theoretical literature follows trends and developments in economic data. Time series for income, unemployment, investments, industrial production, inflation rates, SP stock market index and bankruptcy rates in the USA, as well as the bibliometric series are detrended by the Kalman filter in order to estimate cycles. This step is also performed for the bibliometric series To then determine the connection between economic activity and developments in the academic literature, Granger causality tests are applied.

The discussion begins in Section 2 with an overview of related literature in two fields: Work which discusses the cyclicality and connection to business cycles and crises of economic literature, and bibliometric studies. Section 3 contains the core of the empirical analysis. In Subsection 3.1, the data used and methods employed - both for the bibliometric and econometric analyses - are laid out in detail. Results are presented in Subsection 3.2 and discussed in Section 4, which will also put the results into perspective, theoretically analyze their implications, highlight additional findings, and furthermore discuss caveats. The paper then concludes with a summary of the results. 


\section{Theoretical background and related literature}

In his paper on "Cycles in the history of economic ideas" (own translation), Neumark $(1975,257 \mathrm{f}$.) argues that old ideas, which may have gotten out of fashion, may very well resurface many decades later, and that the overall development of economics is therefore of a cyclical nature and not following a straight upward trend towards ever improved new approaches (also see Kurz 2006). This rather general observation covering various fields of economics overall gains a very peculiar interpretation within the context of discussions of business cycles and crises in particular. Here, a similar argument can be put into perspective of actual economic developments, namely that particular notions, ideas and theory areas resurface in conjunction of particular policy issues and problems over the course of a business cycle, specifically during crises and downswing phases. Expressions such as "panics produce texts" (see Fabian 1989, 128) imply not only a cyclicality in the literature per se, but also one that is correlated with real economic developments. There is also an intuitive appeal to a causality implied by this link: Economic crises and recessions produce an increased interest in the discussion of said events, because obviously, the necessity of dealing with them - e.g. by developing relevant policies - is more urgent than it is at tranquil economic times. Therefore, for example, already John Mills $(1868,11)$, in an article presenting his own analysis of cycles and panics, had observed that "every commercial crisis occurring in this country is promptly followed by a literature of pamphlets". Similarly, Aftalion (1913, 289 f.) argues that countless articles appear with every crisis, an observation which was shared a decade later, with the additional experience of yet another crisis, by Richter (1923, 153). Another ten years later, Durbin $(1933,17)$ asked for caution when dealing with theories arising in these circumstances, for despite potentially being wrong, they might gain ground given the particular context. ${ }^{1}$

Furthermore, two particularly notable examples which are suited to anecdotally confirm this story come to mind: First of all, there is Irving Fisher's debt-deflation theory (see Fisher 1932, 1933), which he devised after his own experience with the Great Depression. And then there is, of course, Keynes's General Theory (1936) and the subsequent rise of Keynesianism, as well as The Return of the Master (Skidelsky 2009) in the context of the 'Great Recession'. While the latter was more than business cycle theory, of course, it has been argued, e.g. by Johnson (1971, $3 \mathrm{f}$.), that the success of the Keynesian revolution can at least partly be explained by its providing answers to urgent problems for economic policy - unemployment caused by the Great Depression - which previous orthodoxy or theory had not been able to do, at least not to this extent. Therefore, on this instance, it might be paraphrased that "panics popularize texts". Furthermore, Keynes's "return"

\footnotetext{
${ }^{1}$ See Besomi (2011, 55 f.) for more detail on these references.
} 
can be seen as an instance both of a resurfacing of old ideas after many decades, and as fueled by the "panics produce texts" story during times of recession: It is not merely the discussion of business cycle and crisis theory in general which had gained in popularity, but a very specific theory at that.

Strictly speaking, though, the "panics produce texts" argument so far would not necessarily imply a cyclicality connected to cycles in economic activity just yet. The statement that during recessions, interest in business cycle and crises theory increases does not automatically imply that it decreases during a boom. Here, it may be tempting to refer to discussions of the postwar economic boom, when Western economies had experienced two decades of prosperity with only very mild recessions in the 1950s and 1960s. Set into this context is the famous volume edited by Bronfenbrenner (1969), with the eponymous question Is the Business Cycle Obsolete?, which had been the theme of a conference in London in 1967. However, two caveats apply here. First of all, the Bronfenbrenner volume was primarily concerned with the question of whether or not business cycles had disappeared (to some extent) from economic data, and not so much what this implied for theory. Also, it should be reiterated, as in Allsopp's review (1971), that the predominant characteristic of the post-war years had been high, and not so much steady, growth rates. Still, whereas during the "years of high theory" (see Shackle 1967) business cycle theory had seen the discussion of a wide array of approaches, and while the 1930s, 1940s and (early) 1950s had seen important developments in postKeynesian business cycle theory, culminating in Hicks's Contribution to the Theory of the Trade Cycle (1950), the overall interest seemed to have decreased and made way for growth theory. Another example of a similar tendency is more recent: Against the background of the long expansionary phases and short recession times of the 1980s and 1990s (and the postwar years in general), Walsh (1999) refers to Bronfenbrenner's volume (also see Romer 1999) and raises the same question. A few years later, shortly before the onset of what has soon afterwards been labelled the 'Great Recession', notable economists such as Robert Lucas, looking back on the previous years of the 'Great Moderation', claimed that "the central problem of depression prevention has been solved" (Lucas 2003, 1).

Whatever the work cited so far argued about a potential cyclicality in the literature, it has done so on the basis of qualitative readings of academic work and anecdotal examples. In general, bibliometric analysis in the history of thought is a very recent topic indeed, which only became possible due to the digitalization of the academic literature which has progressed immensely over the last decade. Even though at the present point, work in this direction is still an emerging field, there are already some examples of research in the history of economics which use these newly available data to answer older questions, or to provide more precise and more specific results. For example, Cardoso et al. (2010) use EconLit and 
Social Science Citation Index (SSCI) data in order to investigate which regions of the world contributed to influential economic research. Diamond (2009) compares the influence of Keynes and Schumpeter through time, using SSCI data. In a more extensive work with the SSCI, Kim et al. (2006) identify the most cited papers in economics since 1970 and document their characteristics, background etc. Similar data are used by Laibson and Zeckhauser (1998) to point out the relevance of some behavioural economics research. A more detailed analysis of behavioural economics based on SSCI and JSTOR data is provided by Geiger (2014).

Considering the present paper's research interest, there is one previous work on both the bibliometrics of business cycle and crises theory and their connection to economic history, namely a study by Besomi (2011), which, according to the author, was the first of its kind to date (see Besomi 2011, 56). In the appendix and introducing discussion of that article, Besomi $(2011,113-117)$ documents the cumulated absolute frequencies of the titles of different kinds of contributions (journal articles, books, pamphlets, etc.) from various sources, most notably JSTOR and EconLit, but also the author's own assembled records for earlier years, which contain terms related to crises and business cycles. The terms themselves are identified based on a comprehensive study (which constitutes the larger part of the article) of the respective literature. In a next step, Besomi (2011, 55 ff.) subsequently discusses these numbers, with a specific interest in the question of whether or not "panics produce texts", i.e. whether the discussion of economic crises and business cycles is more prevalent during hard times of economic distress. By reference to a number of different works, Besomi $(2011,56)$ notes that this thesis of a correlation has been frequently stated, but not quantitatively assessed before his work. However, Besomi's data confirm the casual observation.

Besomi's article clearly is a seminal first step to provide an organized and structured answer to the questions underlying the present paper as well. It provides a nice summary and a general impression, but the method is still fairly unsystematic. Two points are of particular concern: First of all, Besomi discusses only absolute, not relative frequencies. This may be sufficient for a comparison of subsequent years, but for observations over longer time periods, especially over the past century in which the body of academic literature has expanded greatly, there is a substantial risk of systematic errors. As long as the reference group is not included explicitly in a quantitative manner as well, the data cannot be detrended accurately. Furthermore, concerning the second research question, Besomi's approach here is entirely anecdotal, referring to individual historical examples of economic crises without using actual available data and applying statistical methods or running any econometric tests. Besomi is, of course, aware of these shortcomings (see, for example, 2011, 118 Fn.). Still, they should be pointed out because they illustrate clearly what the present paper will contribute in extension of and going 
beyond Besomi's work: it will improve on the method for both research questions, especially the second. Furthermore, whereas the empirical documentation constituted only a small part of Besomi's long article, the present paper is fully dedicated to this analysis. The method will be illustrated in detail in the following, in particular in Subsection 3.1.

\section{Empirical analysis}

The following Subsections illustrate the method, employed data, and main empirical findings of this paper. An analysis which embeds these results in a theoretical context, especially in discussions within the history of economic thought literature as outlined in the previous Section, subsequently follows in Section 4.

\subsection{Method and data}

In order to answer the present paper's research questions, i.e. whether business cycle theory is in itself cyclical, and whether these movements are related to actual economic developments, two steps of analysis will be made. The first is a bibliometric study of trends in economic research with comprehensive data reaching back well into the second half of the 19th century. Following an overview of the bibliometrics, the economic data used are outlined. The Subsection closes with a summary of the econometric methods applied.

\subsubsection{Bibliometrics}

Since bibliometrics is a fairly recent topic, the sources and methods used to extract these data deserve to be discussed in some detail. There are various possible sources for bibliometric data, and different ways to answer respective research questions. Since the present paper is concerned with broad developments, not just particular works of individual authors, it will concentrate on an analysis of frequencies of central notions. That is, the bibliometric data used will be numbers and relative amounts of items in the (English) academic literature which feature a certain term at least once in the text. The terms searched for will be those central to business cycle and crises theory identified by Besomi (2011). Bibliometric time series for these are constructed using data from JSTOR's 'Data ForResearch' (DFR, $<<$ http://dfr.jstor.org/ $>>$ ) tool, which has previously been employed extensively to the same end by Geiger (2014).

Dating back to the second half of the 19th century, JSTOR archives over two hundred periodicals in its 'Economics' subject category, and even more in its 'Busi- 
ness and Economics' subject group category (which includes the former). ${ }^{2}$ All the documents are digitalized with optical character recognition, allowing for full-text searches by DFR, which can be restricted by different categories. The following analysis will be performed, first and foremost, for research articles in journals (i.e. excluding book reviews, editorial items, etc.). This is in order to analyze a fairly homogenous body of literature, and one that represents the majority of the most relevant work, especially in the more recent decades. ${ }^{3}$ JSTOR also includes the large majority of high-ranked journals (according to the RePEc Aggregate Ranking, $<<$ http://ideas.repec.org/top/top.journals.all.html $>>$ ). The underlying data therefore constitute a very large sample of the full population of relevant research in economics journals. It should be noted that JSTOR's archive is less comprehensive than the American Economic Association's EconLit database, but given DFR, it is far more suitable for full text searches of key terms and a subsequent identification of the relevant numbers.

Following the aforementioned contribution of Besomi (2011), data are gathered for 14 key notions. ${ }^{4}$ The DFR search terms used are as follows: 'bubble', "'business cycle", "'business cycle" OR "trade cycle"'(further also 'BCTC'), 'crisis', 'cycle', 'depression', 'distress', 'embarrassment', 'fluctuations', 'glut', 'panic', 'prosperity', 'recession', 'stagnation' and "trade cycle". With the search parameters as seen here, all journal articles which include at least one of the terms anywhere in the

\footnotetext{
${ }^{2}$ Obviously, the 'Economics' category is the most straightforward and primarily important one here, since it can be expected to most closely reflect developments in the theoretical literature, which are the main interest of the present paper. However, it may well be argued that business cycles and crises are such general phenomena that they should be discussed in related fields i.e. the overarching 'Business and Economics' category - as well. Hence, the following analysis will be performed for both sets of reference groups.

${ }^{3}$ Of course this also excludes books, whether miscellanies or monographs. If economics became more article- and less book-oriented, especially since the 19th century, this could imply the risk of systematically wrong assessments of the earlier decades of the time frame observed here, especially since the sample size for the 19th century is still fairly small. However, for a key term analysis (in contrast to a citation analysis, where important individual sources might be left out when not including books), this should pose no major problems, as long as content in books does not systematically employ different key terms from journal articles when discussing the same issues - an assumption which seems plausible. Still, it should be pointed out that in one respect, therefore, the present analysis is less comprehensive than that of Besomi (2011): it includes only research articles, no other items. However, this also makes the sample used here more consistent, since the other items Besomi (2011) uses are not available in a comprehensive manner similar to journal archives.

${ }^{4}$ One of the terms Besomi (2011) lists, namely 'confidence', is left out here. This is because results for 'confidence' can be expected to be less reliable, since any econometric paper reporting confidence levels on its results will contain the term, no matter which topic it discusses.

${ }^{5}$ This is in order to account for the fact that especially in British literature, 'trade cycle' had been the term of choice describing the same concept for a long time, e.g. in Keynes (1936) and Hicks (1950).
} 
document are counted.

It is important to highlight that these terms bear different theoretical connotations (for more on this, see the discussion in Section 4). For example, there are those referring to the general phenomenon ('business cycle'), whereas others highlight a particular point ('crisis') or a phase ('depression', 'prosperity', 'recession'). These are the terms which are most directly linked to business cycle and crises theory without too many obvious theoretical applications connected to different meanings and interpretations elsewhere in the economic literature. Therefore, they will be central to the following analysis. Furthermore, it is also possible that the terms' particular meanings have changed over time. To capture such an evolution, a semantic analysis of the occurrences would be warranted, which could highlight, for example, which terms the particular key notions most frequently appear in conjunction with, etc. Arguably, 'depression' may bear somewhat different implications in 1920 than in 2000. However, this is a further question, and it will not be analysed in detail here, albeit touched upon in the discussion (Section 4). The focus in the present paper is on notions and their frequency, without an in-depth analysis of what these may actually mean (on this issue, also see Besomi 2011). Nonetheless, to also capture the relative importance of, respectively discussions on the matter in general, index values are compounded and included in the analysis as well. Two indexes which depict relative frequencies of papers containing at least one of the respective terms are constructed: a "downswing" index which contains 'crisis', 'recession, and 'depression', and an "overall index" which features all terms.

To provide just a short impression of the numbers, for the time frame 18502010, there are just over 140,000 journal articles in the 'Economics', and over 600,000 in the 'Business and Economics' categories. This is a vast body of literature which could not be analyzed by reading every single paper. However, broad trends in it can be dissected by a bibliometric analysis. Since the items are not spread evenly over time (instead, the body of academic literature published each year has grown and fluctuates annually), the following analysis will work with relative numbers, i.e. the percentage of articles which contain a particular term (such as 'business cycle') relative to all articles in the comparison group (items in 'Economics' and 'Business and Economics' per corresponding year), based on own calculations. That is, if the relative frequency of 'crisis' is $x \%$ in a given year, then $x \%$ of all articles in the respective category for that year (which will be indicated) contained the word at least once in the text. Of course, such a method of counting does not differentiate - as a proper and informed reading of an article could between how intensely a topic was discussed, with which intention this may have been done, whether a contribution was purely theoretical etc. These shortcomings will be analyzed in more detail in the discussion in Section 4 . 


\subsubsection{Economic variables}

In order to gauge economic activity, data for the United States will be used. This introduces an element of inaccuracy, since obviously, economists - especially those from other countries - are concerned with more than just U.S. developments. Nonetheless, it seems a reasonable approximation to use data for the world's largest and leading economy (throughout almost all of the time frame for which reliable data are available), especially when working with a body of mostly English literature.

As indicators for macroeconomic activity, time series for real GDP per capita, the unemployment rate, gross private domestic investment, the consumption price index (CPI), the $\mathrm{S} \& \mathrm{P}$ stock market index, and a measure of bankruptcy rates is included. Table 1 lists all these variables and also the range they cover. The data on income, investments, unemployment and industrial production was taken from the FRED. ${ }^{6}$ CPI data are from the long series of Officer and Williamson (2015). The data on the stock market S\&P composite index was taken from Shiller (2015) and the bankruptcy rates were taken from Garrett (2007).

Table 1: Economic variables

\begin{tabular}{llr} 
Economic stationary cycles & \multicolumn{1}{c}{ Description } & Time frames \\
\hline cLNRINCOME & Log of real GDP per capita & $1871-2012$ \\
cUN & Unemployment rate & $1948-2012$ \\
cLNINVEST & Log of real gross private domestic investment, Index $2009=100$ & $1929-2012$ \\
cLNPROD & Log of the industrial production index, Index 2007=100 & $1919-2012$ \\
cLNCPI & Log of consumption price index, Index average 1982-1984=100 & $1851-2012$ \\
cLNSP & Log of the S\&P composite index & $1871-2012$ \\
cLNBANKR & Log of bakruptcy rates per 1000 capita & $1900-2005$
\end{tabular}

\subsubsection{Econometric methods}

We first test the stationarity of all variables, both bibliometric and economic, by means of the Augmented Dickey-Fuller test with Generalized Least Squares (further ADF GLS) as in Elliott et al. (1996). From the test results it follows, that all of the bibliometric and economic variables can be regarded as random walks and need to be transformed. Before the transformation, we apply the Johansen cointegration test (Johansen, 1988; Hamilton, 1994) to check if there exists cointegration between the variables. The transformation to achieve stationarity is performed with the help of the Kalman filter as in Petris et al. (2009, 51-62). We use the "dlm" package (Petris, 2010) and set a first order polynomial model for filtering. The parameters for the filter are estimated with the help of the maximum

\footnotetext{
${ }^{6}$ Retrieved on April 22, 2015 from FRED, Federal Reserve Bank of St. Louis $<<$ https://research.stlouisfed.org/fred2/series/CFMMI/ $>>$.
} 
likelihood function. The Kalman filter yields stationary cyclical fluctuations, indicated with a "c" before the respective variable name, which are used in the further analysis. One of the well-established techniques representing causal inference in time series is the VAR framework, as in Hamilton (1994, Chpt. 11). Once the VAR analysis is conducted we derive the impulse-response functions and perform the Granger-causality test, as in Granger (1969). Finally, we check that the residuals of our models are white noise with the Portmanteau Q test as in Ljung and Box (1978).

$$
\begin{aligned}
& y_{t}=c_{1}+\pi_{11} y_{t-1}+\pi_{12} x_{t-1}+e_{1, t-1} \\
& x_{t}=c_{2}+\pi_{21} y_{t-1}+\pi_{22} x_{t-1}+e_{2, t-1}
\end{aligned}
$$

Where $y_{t}$ denotes cyclical fluctuations in the economic variables; $x_{t}$ denotes cyclical fluctuations in bibliometric variables; $c$ denotes a constant, whereas $\pi$ denotes coefficients; $e$ is an error and $t-1$ is the lag operator. For simplicity we display the first order VAR, but the optimal lag length is determined for each case with the help of AIC, HQIC and SBIC according to the parsimony principle.

A short note should be made on the Granger causality test. One should specify that the Granger causality test is a special case of causal inference, which represents a statistical test of the significance of the VAR coefficients. As Granger (1969, p. 428-429) notes, this type of causality emerges when certain variables help to predict (or help to improve the forecast of) the future values of others. Applied to our paper, the null hypothesis of the test can be formulated in the following way: economic variables $y_{t}$ do not Granger-cause bibliometric ones $x_{t}$. This means that if a Granger causality from the economic variables to the bibliometric ones exists, that is if we reject the null hypothesis and assume the possibility of the existence of Granger causality, then the current economic situation helps to predict the future bibliometric series. Thus, the concept of Granger causality should be treated in a technical manner, rather than philosophical; it does not yet come with a theoretical argument to explain potential causalities. In order to put the results in a general context and allow for a more comprehensive discussion, Granger causality tests are also performed for the opposite direction, i.e. from bibliometric variables to economic data with the null hypothesis changed respectively.

\subsection{Empirical results}

This Subsection documents the empirical results. Starting with a descriptive overview, the limitations of this approach (i.e. its inability to fully capture systematic relations) and therefore the necessity of the econometric tools, illustrated in the previous Subsection, to provide formal supportive arguments for the research questions is pointed out. A discussion of the results follows in Section 4. 


\subsubsection{Bibliometric results - descriptive overview}

Figure 1 provides a general impression of the bibliometric data and respective first results. It displays the relative frequencies of the four arguably most relevant search terms for papers within JSTOR's 'Business and Economics' category, namely 'BCTC' (blue), 'crisis' (red), 'recession' (green), and depression (yellow) from 1850 to 2012. Some characteristics of these time series immediately catch the eye. For example, the terms 'crisis' and 'depression' have already been in frequent use much longer than the other two. The series for 'BCTC' and 'recession' have been without breaks (i.e. years with no paper featuring either term) since 1909 and 1907 respectively, and, overall, are closer o one another than to the two older time series. A closer look at the 'BCTC' series further reveals the relative importance of 'business cycle' and 'trade cycle' respectively (not displayed in the figure): 'business cycle' has been the far more frequent term overall and throughout, appearing in over eight times as many papers. The frequency of 'trade cycle' peaked in the late 1930s and early 1950s, and then diminished. In the 2000s, only about $0.1 \%$ of all journal articles contained the term, whereas 'business cycle' appeared in about $4.5 \%$.

When looking at the 'recession' line, marked fluctuations are evident. Around every ten years, there is a pronounced peak in the series. Overall, though, these fluctuations are around a fairly steady, slightly rising trend. With 'BCTC', on the other hand, there are less pronounced fluctuations, but a clear shift in trends: From the 1940s until around 1970, the relative frequency declined, and then slowly rose again, reaching similar levels to the late 1930s in the 2010s.

Comparing these two lines to the remaining two allows for further interesting observations. First of all, for almost the whole period, both 'depression' and especially 'crisis' appeared more frequently than the other two. Both had peaks in the early 1930s (whereas 'BCTC' and 'recession' peaked in the late 1930s). The relative frequency of 'depression' steadily declined from the immense height of over $30 \%$ per year in $1932-1937$ to just around $5-6 \%$ in the 1970 s and following decades, i.e. on a level with 'BCTC' and 'recession' in the most recent years. On the other hand, the relative frequency of 'crisis' has steadily, albeit with some notable up and downs along the movement, increased since the 1970s. 
Figure 1: Relative frequencies of selected bibliometric variables.

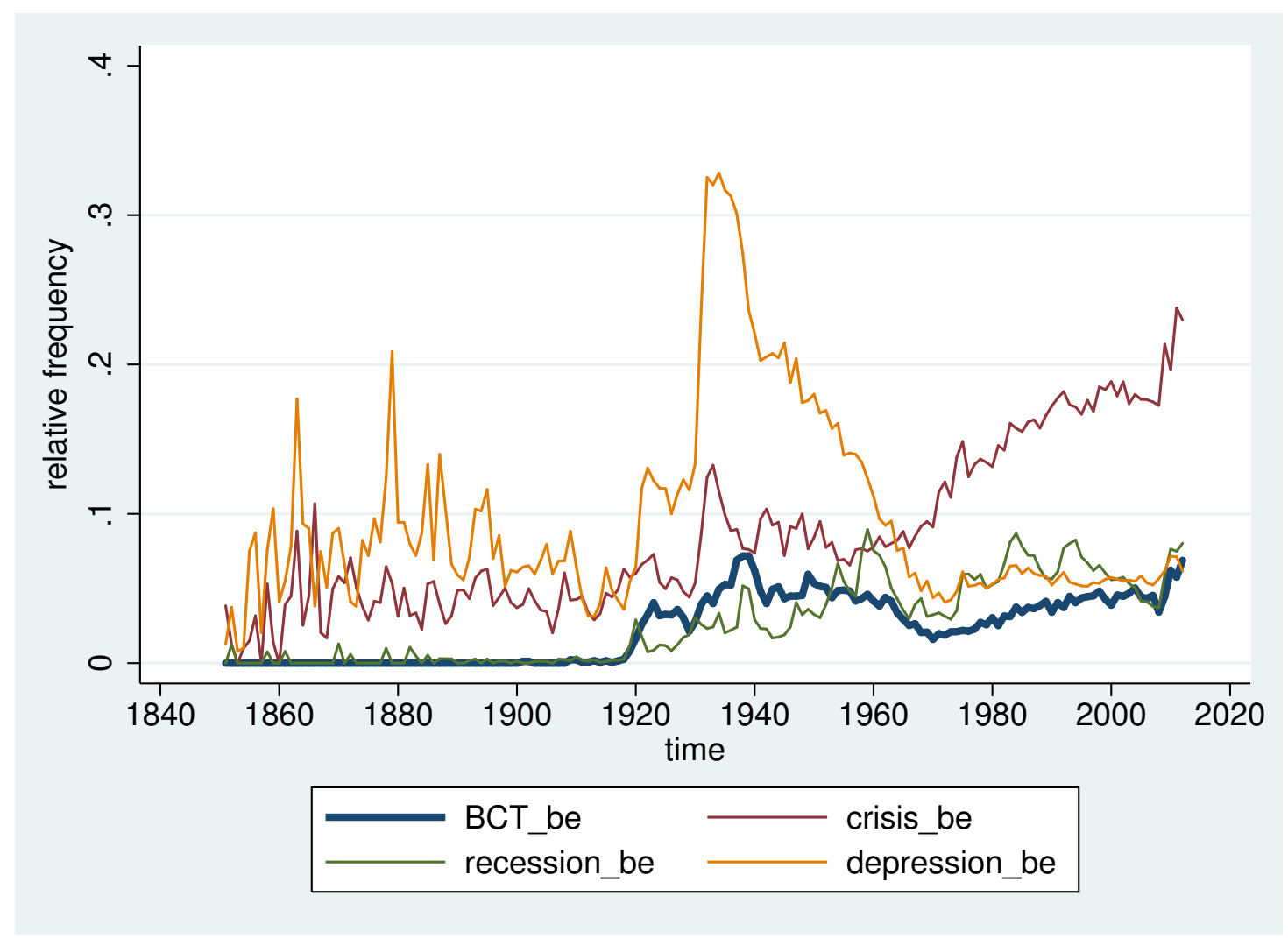

Figure 1 already displays some strong results which may allow for straightforward inferences (see Section 4 for a discussion). At the same time, therefore, these results raise the question of why sophisticated econometric methods such as those presented in Subsection 3.1.3 to be used in the following analysis should be necessary. Figure 2 illustrates the problem and corresponding necessity.

In Figure 2, the time lines for the unemployment rate (dotted line, right hand scale) and relative frequency of 'recession' within the 'Business and Economics' category (green, left hand scale) are plotted against one another. Both a first glance, and even a closer, but purely descriptive, observation immediately reveal the close parallels between peaks and troughs. The apparent lag between peaks and troughs in both lines is also in the expected, theoretically and intuitively appealing direction: Peaks in unemployment come before those in the bibliometric series. What is more, the two lines are close to one another even on almost the same level - the scale on both sides is almost equal. Therefore, it seems safe to conclude that the discussion of recessions in the literature is strongly connected to changes in the unemployment rate. 
However, actually testing this hypothesis with more thorough statistical methods quickly leads to the necessity of putting this impression into perspective. Already the Johansen cointegration test (see Table 8) reveals that the two time series, interestingly, are not cointegrated according to the test, which may seem counterintuitive. Clearly, though, a standard test has better claims to objectivity than a descriptive observation finding intuitively appealing results. Therefore, a more rigorous econometric approach to properly validate the results seems justified.

Figure 2: Unemployment and relative frequency of 'recession'

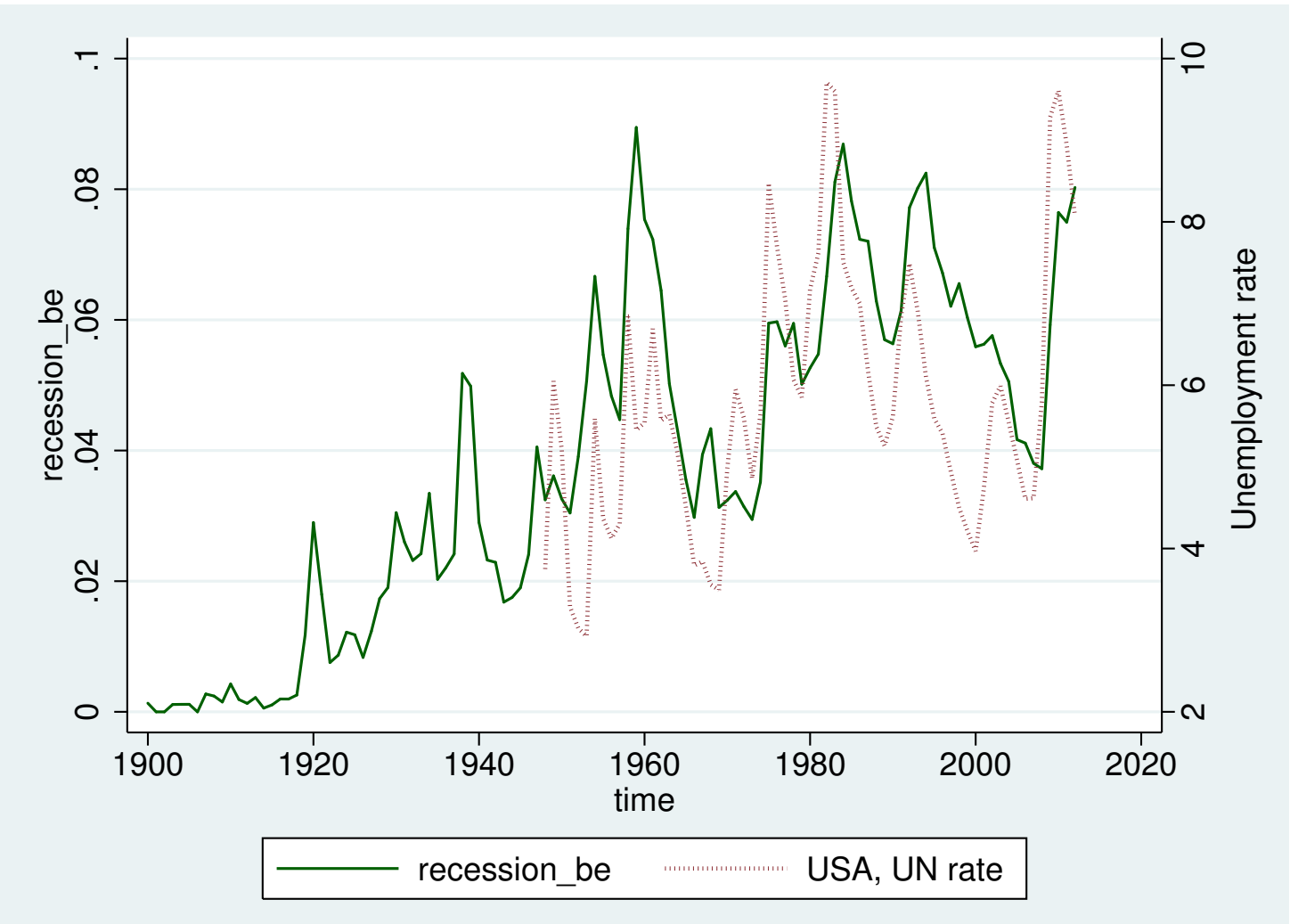

\subsubsection{Business cycles in the economy and in economics}

According to the ADF GLS test all of the variables are not stationary and therefore we apply the Kalman filter to obtain stationary bibliometric and economic cycles. The Johansen cointegration test results suggest no cointegration (see Table 8) between the economic and the bibliometric variables. Additionally, we do not find cointegration between the bibliometric variables as well. Therefore, we can proceed to transforming the variables and applying the VAR framework. We 
use bivariate VARs and maximize the time frames of our analysis, rather than selecting a uniform time period for all the variables. Selecting a uniform time period for all variables would result in a loss of observations and a higher small sample bias. The number of observations varies from 61 to 156 for different VARs. Even though we strive to use the longest time frames available, we correct our VAR for the small sample size and therefore the Granger causality test and results in Tables 2-5 already include this adjustment. The lag length for the VARs is selected according to Akaike, Schwartz Bayesian, Hannan-Quinn information criteria and the forecasting prediction error as in Nielsen (2001). The optimal lag lenght of the VARs variates from one to eight lags and the principle of parsimony is applied. Whereas tables 2-5 contain the Granger causality test results, Table 6 reports the $\mathrm{Q}$ test for the white noise in residuals. The latter is necessary to filter out results of the models, which fail to produce residuals with constant variance and zero mean. We use the $5 \%$ benchmark for all the tests applied, including the $\mathrm{Q}$ test for white noise. In addition, we differentiate between Granger causality in the direction towards bibliometric variables, instantaneous Granger causality (Granger, 1980, 340) and Granger causality in the opposite direction. The formulation of the null hypothesis of the Granger causality test applied in this paper is that economic variables do not Granger-cause bibliometric ones. Therefore, at levels lower than $5 \%$ we reject the absence of Granger causality and assume either Granger causality in the direction of bibliometric variables, instantaneous or reverse Granger causality. The white noise Q test applied allows us to accept or reject the null hypothesis that the residuals of our VARs are white noise and have a constant variance and a zero mean. Values less than $5 \%$ benchmark would suggest that the residuals are not white noise and therefore the related results are questionable.

We first discuss the results related to the literature from 'Business and Economics' (Tables 2 and 4) and then validate them with the help of the sample from the 'Economics' subset only (Tables 3 and 5). Let us start with highlighting the Granger causality from economic variables to the bibliometric ones and therefore investigate whether the economic 'panic' indeed produces scientific works. The p-values from Table 2 point out Granger causality for the main economic variables of interest. It appears that on the $5 \%$ we can assume that the cyclical fluctuations of real income per capita Granger-cause bibliometric data on 'panic', 'stagnation' and the 'overall' index; the cyclical fluctuations of unemployment Granger-cause 'fluctuations', 'business cycle' and 'prosperity'; cyclical fluctuations of real investments Granger-cause the most bibliometric variables, namely 'fluctuations', 'business cycle', 'crisis', 'cycle', 'panic', 'stagnation' and the 'overall' index; cyclical fluctuations of industrial production Granger-cause 'BCTC' and 'recession'; cyclical fluctuations of CPI Granger-cause 'business cycle'. From Table 4 with additional economic variables we find that the cyclical fluctuations of 
the S\&P composite index Granger-cause bibliometric data on 'crisis', 'depression' and the 'downswing' index. The cyclical fluctuations of bankruptcy rates per 1000 capita Granger-cause only fluctuations in literature related to the term 'bubble'.

Tables 3 and 5 focus only on the literature from the 'Economics' sphere and validate our hypothesis on the relation between economic and bibliometric variables: cyclical fluctuations of the real income per capita Granger-cause 'distress', 'panic' and the 'overall' index; cyclical fluctuations of real investments Grangercause 'business cycle', 'crisis', 'cycle', 'panic', 'prosperity' and the 'overall' index; industrial production Granger-causes 'BCTC', 'business cycle', 'cycle' and 'stagnation'; CPI Granger-causes 'embarrassment'. For the additional variables, the results from the 'Economics' literature validate exactly the same causalities, obtained in Table 4. In general, for the 'Economics' literature we were able to find 18 incidents of Granger causality from the economic variables to the bibliometric ones, whereas in the 'Business and Economics' category we found 20 such incidents.

The instantaneous Granger causality can be found for the following cyclical fluctuations: unemployment and 'BCTC', 'cycle' and 'recession'; real investments and 'BCTC', 'depression' and 'distress'; industrial production and 'business cycle' and 'cycle'. One has to note that this instantaneous phenomenon is rare, compared to the Granger causality from economic to bibliometric cycles.

Tables 3 and 5 with 'Economics' literature show similar instantaneous Granger causalities: between the cyclical fluctuations of the real income per capita and 'crisis'; unemployment and 'BCTC', 'business cycle', 'cycle' and 'recession'; real investments and 'depression' and 'distress'; industrial production and 'bubble' and 'recession', CPI and 'recession'. The share of instantaneous Granger causalities in the sphere of 'Economics' is slightly higher compared to 'Business and Economics'.

The opposite direction of Granger causality, i.e. from bibliometric data to economic variables, is also worth mentioning. This phenomenon can be detected for cyclical fluctuations in real income per capita and 'distress', 'prosperity' and the 'downswing' index; unemployment and 'stagnation'; investments and 'depression', 'distress'; industrial production and 'bubble'; CPI and 'panic', 'prosperity' and 'stagnation'. From Table 4 we find such causality for cyclical fluctuations of the SP index and 'stagnation' as well as bankruptcy rates per 1000 capita and 'recession'. Finding Granger causality in this direction, i.e. opposed to the one expected, may be surprising, and is discussed in detail in the discussion (Section 4)

In Tables 3 and 5 we find reverse Granger-causality for: real income per capita and 'prosperity' and the the 'downswing' index; CPI and 'fluctuations'; bankruptcy rates per 1000 capita and 'recession'.

All the VARs are checked for stability and they fulfill the related conditions. As seen in Table 2, there exists a simultaneous Granger-causality between the cyclical fluctuations of income and bibliometric data on 'fluctuations', however, 
the white noise test results from cell A1 in Table 6 suggest that the residuals from this VAR are not white noise and therefore this Granger-causality test result should be treated with extreme caution. Same applies to A7, E2 and F9. We refrain from reporting the related Granger causality test results due to the fact that the residuals for these VARs are not white noise. Table 7 tests the residuals from models related to the 'Economic' literature (from Tables 3 and 5). In the latter case, none of the causal incidents are rejected because of the test for white noise and only the residuals from $\mathrm{H} 2$ and M2 do not pass the test.

The selected impulse-response functions from Figure 3 allow us to conduct simulation based on our VAR estimation. These simulations show how and how long the literature reacts on economic variables: a positive impulse from unemployment causes a positive reaction of the bibliometric data on 'business cycle', whereas positive impulses from investments, industrial production and the SP index cause a negative reaction of bibliometric data on 'crisis', 'panic', 'recession', 'BCTC' and 'crisis'. One should note that most of the functions converge after 4-5 steps.

Bearing Graph 3 in mind, one could use the simulated impulses to quantify the impact of economic variables on literature in the sphere 'Business and Economics': a $1 \%$ increase of the unemployment rate in the previous year leads to a 0.0266 percentage points increase in the 'business cycle' in the current year; a $1 \%$ increase of the real investments in the previous year leads to a 0.4339 percentage points decrease in the 'crisis' in the current year; a $1 \%$ increase of the real investments in the previous year leads to a 0.1116 percentage points decrease in the 'panic' in the current year; a 1\% increase of the industrial production in the previous year leads to a 0.3189 percentage points decrease in the 'recession' in the current year; a $1 \%$ increase of the industrial production in the previous year leads to a 0.1544 percentage points decrease in the 'BCTC' in the current year; a $1 \%$ increase in the SP stock market index in the previous year leads to a 0.4415 percentage points decrease in the 'crisis' in the current year. The above-mentioned effects refer to the first-year after the impulse and are purely illustrative.

In practice, one could interpret this in a following way: economic variables usually have the strongest impact on the economic literature in frames of the first 1-5 years after the impulse. Obviously, Figure 3 shows only a small number of IRFS, and not even all of the relations for which positive Granger causality results were observed. Their patterns, however, are characteristic, which is why they were selected. 
Figure 3: Selected impulse-response functions, for Tables 2 and 4

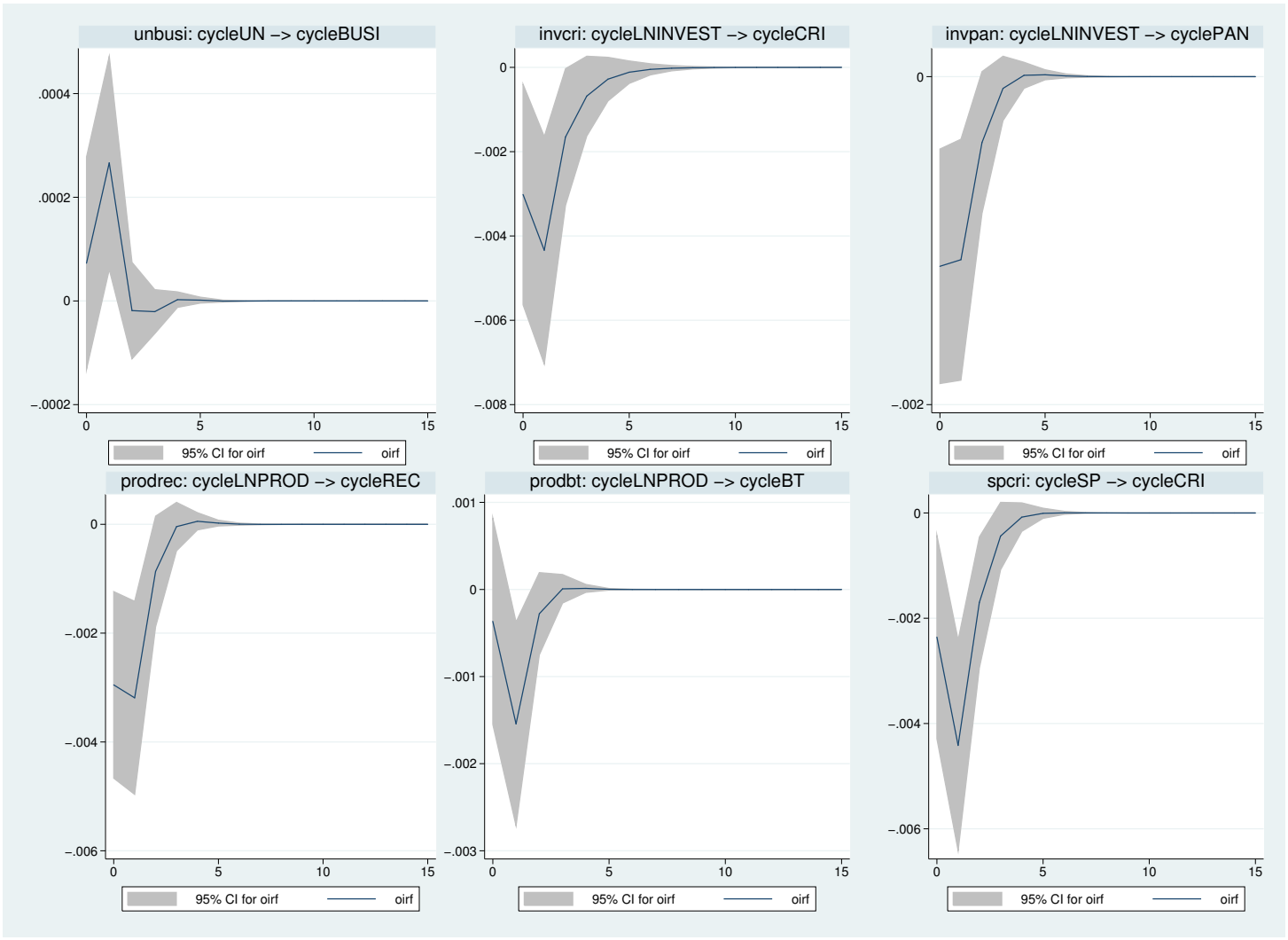

\section{Discussion}

It is important to discuss the instantaneous and the opposite or the reverse Granger causality, found in Tables 2-5. Regarding the instantaneous Granger causality, we consider this finding as a positive evidence of interaction between the state of the economy and scientific activity. As it follows from Granger (1980, 340), such instantaneous phenomena can be related to measurement issues: the frequency of our data is annual, whereas the actual causality may occur at higher frequencies. However, bearing in mind the submission process and the review time for scientific literature, considering the series at an annual level is reasonable (and, at any rate, inevitable, given the availability of data). Furthermore, it can also be pointed out that in most instances of instantaneous causality, the significance level on the direction of bibliometric to economic data is much higher than its opposite. Therefore, it may be argued that the effect in the "expected" direction is more significant. 
Nevertheless, we acknowledge the fact that the measurement issue exists and it can be related to the instantaneous Granger causality found for the abovementioned variables. Another potential explanation would be either an exceptional forecasting quality of the related economic literature, which can capture the contemporary trends in the economic data, or the "production function" of the scientific journals and editors: If, during times of an economic crises and recession, journal editors strive to issue and publish papers as fast as possible while the topics are still relevant, an economic downturn earlier in a year may very well co-occur with many discussions on it later in the year - which, given annual data for both variables, may result in instantaneous Granger causality. Considering the reverse causality, one could speculate and assume that there is a policy or sentiment channel, through which the economic literature can impact the economic variables. In this case we could also assume that economic texts can produce 'panics', or at least certain sentiments which can influence economic activity (see e.g. Soo 2013). However, one could also leave room for statistical errors and a missing variable bias which leads to such test results. We should point out that the "reverse" Granger causalities, as well as the instantaneous ones, are rather rare comparing to the Granger causality from economic cycles to bibliometric ones. The reverse causality nonetheless offers a fruitful ground for further research.

Next to the analysis of its main research question, a comprehensive empirical analysis such as the one in this paper of course also comes with some "byproducts" which are noteworthy and, at least in this context, potentially of interest to scholars in the history of economic thought. Some of these are quite apparent from a closer look at Figure 1, which depicted the main descriptive bibliometric results: First of all, it is immediately apparent that 'depression' and 'crisis' are, as it where, older terms than 'BCTC' and 'recession'. What is more, the latter (newer) terms rose in popularity together, and are, overall, closer to each other's frequency levels than to those of 'crisis' and 'depression'. This should be but little surprise to scholars familiar with the history of business cycle theory: Indeed, business cycle theory evolved from crises theory, following the insight that the crisis is but one important turning point in a longer chain of events, i.e. the cycle (see Schumpeter 1931, 6). And it was in the early 20th century, just as the two respective time lines begin their ascent, that this was generally becoming the accepted view (see, e.g., Mitchell 1913, 5; also Dal-Pont Legrand and Hagemann 2007, 12 f.).

When comparing the time lines for 'depression' and 'recession', it is apparent that they moved on similar levels from the 1960s onwards, whereas earlier decades, not just following the Great Depression, had seen much more frequent use of the notion of 'depression'. There is an appealing argument which can be made for this: Overall, after World War II, downswings in business cycles have been much milder on average than previous historical experiences (see e.g. Romer, 1999). This may 
very well explain why the terminology shifted (relatively) more towards the notion - 'recession' - which refers to a less severe period of economic dearth. It is, however, interesting to point out the enormous increase in the relative frequency of 'crisis' since the 1960 s, from under $10 \%$ to well over $20 \%$ in more recent years. This might be interpreted to imply a shift away from discussions of the business cycle as a whole and towards the particular event of the crisis, which might be in accordance with the focus on shocks which is widespread in standard workhorse approaches to business cycle analysis over the past four decades, i.e. the New Classical/Real Business Cycles/New Keynesian literature. The frequency of 'BCTC' also similarly increased since the 1970s, however. Additionally, it may be argued that 'crisis' is a term with a broader applicability, also outside of the mainly macro, business cycle theory context, whereas 'recession' is very specific to the latter.

Overall, the empirical results in this paper have been in accordance with earlier discussion in the literature and, due to their intuitive appeal, quite compelling. The IRF estimates in particular provide a specific quantitative assessment of the illustrated relations: For example, it was demonstrated that a $1 \%$ decrease in industrial production from its trend implies a 0.3189 percentage points increase in the relative frequency of 'recession' in the B\&E category. Given that this frequency fluctuates between $5 \%$ and $10 \%$ historically, this implies a relative change of $3 \%-$ $6 \%$ in the frequency of 'recession' following a $1 \%$ change in industrial production. Despite these strong results, it is important to add some caveats concerning the generality and broad applicability of the results, which owe partly to the data used, but also to the details of the results. One major issue which needs to be pointed out is the method of counting articles. As outlined in Subsection 3.1, any article which contains the particular key term in question at least once anywhere in the text was counted. This means that there is no differentiation between how often the term appears, and in what way the particular notion is qualitatively discussed (which is next to impossible for a broad bibliometric analysis anyway). For example, it might be that the reason behind increased frequencies in the context of crises and recession are no increased theoretical discussions, but a simple shift in introductions to economic texts, whatever their specific topic, which now begin their discussions with observations such as "In context of the recent crisis..." or similar. This might also explain why the fluctuations and corresponding peaks in the 'recession' time line of Figure 1 are more pronounced than in the 'BCTC' series: When a recession hits, it may very well not be the term 'business cycle' which is used in introductions referring the event, but, instead, 'recession'.

The problem of properly counting items might be avoided if instead of searching for terms anywhere in the document, key terms associated with the documents would be analyzed. JSTOR's DFR contains automatically generated key terms (based on frequencies within the document). If a notion such as 'recession' is 
featured among these, it is less likely that there is only lip service done to business cycle theory; but it may also happen that a business cycle theory paper might be excluded because of other, more frequent notions among the key terms (for example, the most frequent key terms in the 'Economics' category include such general notions as 'market', 'price' and 'capital'). Further research can help to clarify this issue and contribute to a more precise understanding.

\section{Conclusion}

The discussion of the theoretical background in Section 2 demonstrated that the research questions guiding this paper are part of a recurring theme in the economic literature, almost as old as business cycle and crises theory itself. With the availability of digitalized archives of the academic literature, it has become possible to answer this question quantitatively, i.e. to provide a more specific and detailed analysis of broad trends than the discussion of any individual paper or small set or papers could.

The results generally confirmed the theoretically appealing intuition based on observations of current events and anecdotal examples which could be found in the earlier literature, i.e. that business cycle and crises theory (more specifically: the frequency of its key notions, especially those related to the downswing) is on the rise during economically hard times, and experiences decreasing interest in prosperous times. However, they also point out that this thesis has to be taken with a grain of salt, and that further research will be necessary to get a more detailed understanding of the relation between business cycles in the economy and in economics. The Granger causalities from the economic variables to the bibliometric data from the sphere of 'Business and Economics' include causalities from: cyclical fluctuations of real income per capita Granger-cause bibliometric data on 'panic', 'stagnation' and the 'overall' index; the cyclical fluctuations of unemployment Granger-cause 'fluctuations', 'business cycle' and 'prosperity'; cyclical fluctuations of real investments Granger-cause the most bibliometric variables, namely 'fluctuations', 'business cycle', 'crisis', 'cycle', 'panic', 'stagnation' and the 'overall' index; cyclical fluctuations of industrial production Granger-cause 'BCTC' and 'recession'; cyclical fluctuations of CPI Granger-cause 'business cycle'; cyclical fluctuations of the S\&P composite index Granger-cause bibliometric data on 'crisis', 'depression' and the 'downswing' index and cyclical fluctuations of bankruptcy rates per 1000 capita Granger-cause only fluctuations in literature related to the term 'bubble'. After testing the residuals for white noise we find 20 Granger causality incidents from the economic variables to the bibliometric ones in the field 'Business and Economics' and 18 incidents in the field 'Economics', including notable intersections, which largely validates our hypothesis. In addition, we 
find incidents of instantaneous and reverse Granger causality; however, their share is lower. Another valuable finding is related to the impulse-response functions. These provide quantitative measures of the effects from economic to bibliometric variables, and further allow us to point out that in general the strongest reaction of bibliometric variables on the economic ones takes place within 1-5 years from the initial impulse.

Even though the analysis and results presented in this paper clearly provide a step forward in answering the underlying research questions of the cyclicality in business cycle and crises theory, and its connection to actual economic developments, there are still caveats to be kept in mind which were discussed in Section 4. Further research may contribute to clarify these issues. For once, the key term analysis may be scrutinized as discussed in Section 4. Furthermore, it is possible to conduct similar analyses as was done for the key terms here, but for citation counts instead of key terms. When taken together, this would allow for a more comprehensive account of the general topic overall, which was not included in the present paper because business cycle and crises theory is such a broad field with such a wide spread (as was evident from the numbers and figures, e.g. in Figure 1) that including more than the terms would have meant far too much data for a single paper. Nonetheless, this demonstrates how many more answers bibliometric research may provide not just for specialists in the history of economic thought, but to anybody interested in the origins and development of their field. 


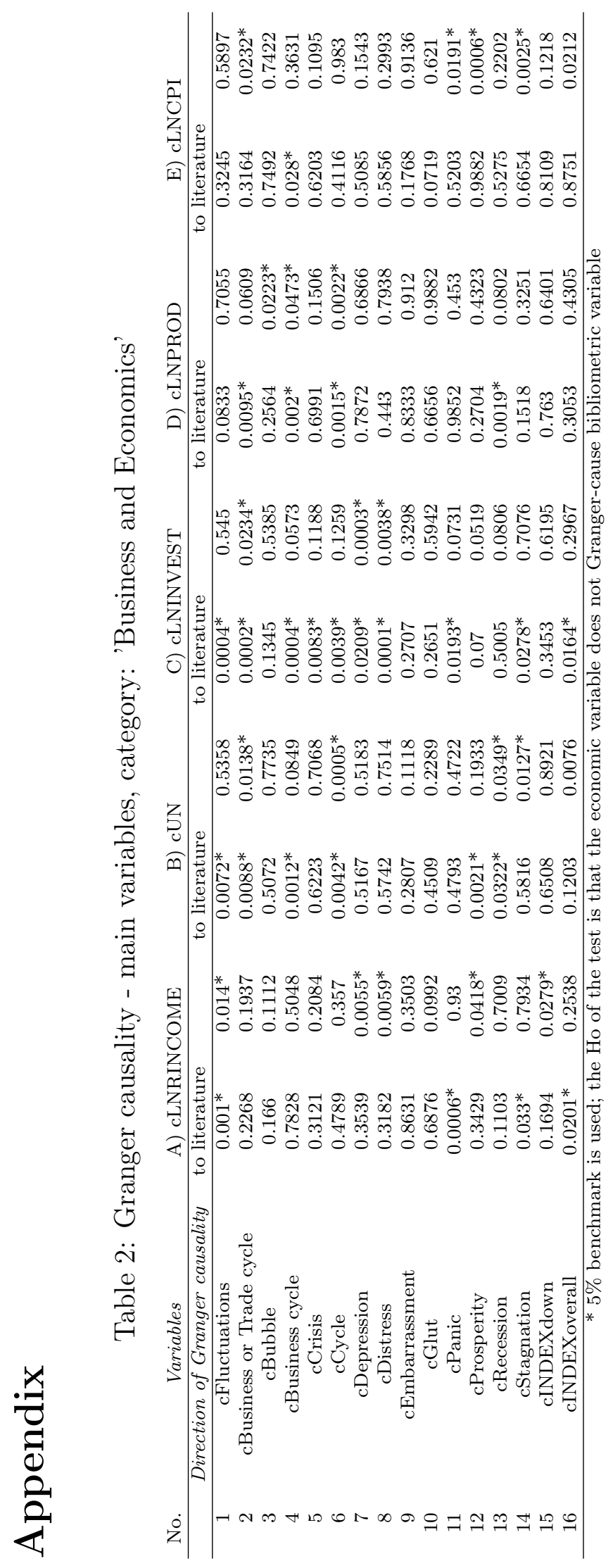




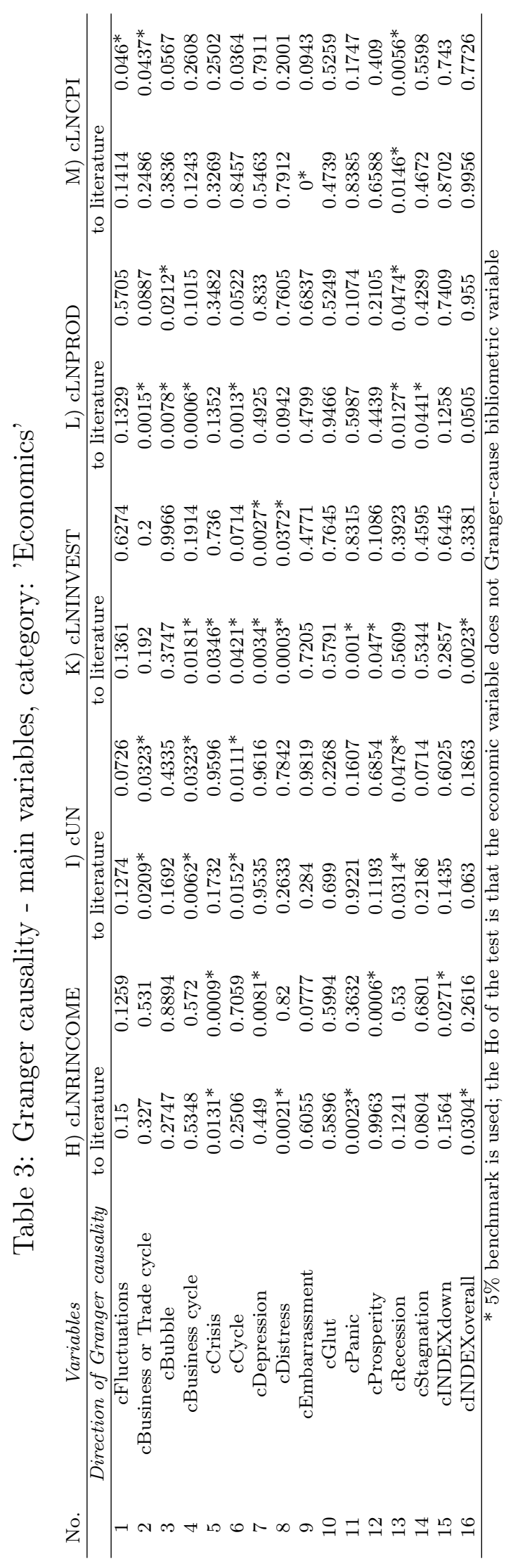


Table 4: Granger causality - additional variables, category: 'Business and Economics'

\begin{tabular}{rccccc} 
No. & Variables & F) cLNSP & \multicolumn{2}{c}{ G) cLNBANKR } \\
\hline \multicolumn{1}{r}{ Direction of Granger causality } & to literature & \multicolumn{3}{c}{ to literature } \\
2 & cFluctuations & 0.6685 & 0.4298 & 0.8462 & 0.976 \\
3 & cBusiness or Trade cycle & 0.3541 & 0.8244 & 0.9174 & 0.7761 \\
4 & cBubble & 0.6456 & 0.7524 & $0.0342^{*}$ & 0.3486 \\
5 & cBusiness cycle & 0.1155 & 0.8289 & 0.87 & 0.7557 \\
6 & cCrisis & $0.0001^{*}$ & 0.4876 & 0.6402 & 0.109 \\
7 & cCycle & 0.4336 & 0.307 & 0.8044 & 0.741 \\
8 & cDepression & $0.0067^{*}$ & 0.3742 & 0.9955 & 0.9617 \\
9 & cDistress & 0.6681 & 0.3418 & 0.2851 & 0.7877 \\
10 & cEmbarassment & 0.7128 & 0.6458 & 0.6341 & 0.9945 \\
11 & cGlut & 0.8004 & 0.6807 & 0.7577 & 0.5011 \\
12 & cPanic & 0.5279 & 0.5777 & 0.873 & 0.9605 \\
13 & cProsperity & 0.3312 & 0.3891 & 0.9686 & 0.9384 \\
14 & cRecession & 0.4714 & 0.6815 & 0.6975 & $0.0156^{*}$ \\
15 & cStagnation & 0.0569 & $0.0227^{*}$ & 0.5403 & 0.9869 \\
16 & cINDEXdown & $0.0005^{*}$ & 0.747 & 0.2106 & 0.6693 \\
\hline
\end{tabular}

Table 5: Granger causality - additional variables, category: 'Economics'

\begin{tabular}{cccccc} 
No. & Variables & N) cLNSP & \multicolumn{2}{c}{ O) cLNBANKR } \\
\hline & Direction of Granger causality & to literature & to literature \\
\hline 1 & cFluctuations & 0.9262 & 0.784 & 0.8927 & 0.9041 \\
2 & cBusiness or Trade cycle & 0.3411 & 0.642 & 0.595 & 0.53 \\
3 & cBubble & 0.6072 & 0.6594 & $0.0142^{*}$ & 0.0785 \\
4 & cBusiness cycle & 0.2452 & 0.8582 & 0.5683 & 0.3362 \\
5 & cCrisis & $0.0001^{*}$ & 0.7588 & 0.1971 & 0.4871 \\
6 & cCycle & 0.2433 & 0.4784 & 0.2127 & 0.2748 \\
7 & cDepression & $0.0411^{*}$ & 0.7185 & 0.8839 & 0.8899 \\
8 & cDistress & 0.5912 & 0.0861 & 0.6929 & 0.6746 \\
9 & cEmbarassment & 0.1727 & 0.7185 & 0.996 & 0.9957 \\
10 & cGlut & 0.7445 & 0.826 & 0.9564 & 0.6006 \\
11 & cPanic & 0.4888 & 0.3873 & 0.5637 & 0.9737 \\
12 & cProsperity & 0.7887 & 0.9907 & 0.6951 & 0.7775 \\
13 & cRecession & 0.5907 & 0.5931 & 0.4522 & $0.0461^{*}$ \\
14 & cStagnation & 0.2055 & 0.2358 & 0.6317 & 0.8316 \\
15 & cINDEXdown & $0.0186^{*}$ & 0.9754 & 0.4191 & 0.3494 \\
16 & cINDEXoverall & 0.2934 & 0.5387 & 0.3596 & 0.543 \\
\hline
\end{tabular}


Table 6: Portmanteau Q test of the residuals, category: 'Business and Economics'

\begin{tabular}{cccccccc} 
No. & $\mathrm{A}$ & $\mathrm{B}$ & $\mathrm{C}$ & $\mathrm{D}$ & $\mathrm{E}$ & $\mathrm{F}$ & $\mathrm{G}$ \\
\hline 1 & $0.0415^{*}$ & 0.956 & 0.8913 & 0.9144 & 0.842 & 0.2693 & 0.5259 \\
2 & 0.5559 & 0.6385 & 0.9279 & 0.9862 & $0.0272^{*}$ & 0.454 & 0.5265 \\
3 & 0.354 & 0.3605 & 0.98 & 0.9601 & 0.3253 & 0.9657 & 0.8786 \\
4 & 0.4216 & 0.835 & 0.9533 & 0.9764 & 0.7992 & 0.7979 & 0.6685 \\
5 & 0.2741 & 0.8396 & 0.1503 & 0.9419 & 0.8452 & 0.2335 & 0.7556 \\
6 & 0.2644 & 0.376 & 0.9631 & 0.972 & 0.8871 & 0.2065 & 0.5372 \\
7 & $0.0037^{*}$ & 0.8212 & 0.991 & 0.9751 & 0.685 & 0.4442 & 0.542 \\
8 & 0.1946 & 0.742 & 0.8531 & 0.9212 & 0.4582 & 0.3448 & 0.5466 \\
9 & 0.7991 & 0.9748 & 0.2234 & 0.8069 & 0.0626 & $0.0157^{*}$ & 0.803 \\
10 & 0.2547 & 0.2718 & 0.9145 & 0.9272 & 0.269 & 0.5673 & 0.6336 \\
11 & 0.2384 & 0.5523 & 0.5669 & 0.9462 & 0.562 & 0.2481 & 0.5636 \\
12 & 0.2596 & 0.5027 & 0.9939 & 0.974 & 0.8931 & 0.2533 & 0.5625 \\
13 & 0.1667 & 0.6252 & 0.9521 & 0.9878 & 0.9876 & 0.4483 & 0.7793 \\
14 & 0.2379 & 0.9738 & 0.1695 & 0.966 & 0.4079 & 0.4641 & 0.4844 \\
15 & 0.1366 & 0.612 & 0.1525 & 0.9359 & 0.1857 & 0.2606 & 0.7095 \\
16 & 0.1753 & 0.5057 & 0.2596 & 0.9463 & 0.313 & 0.2751 & 0.5877 \\
\hline
\end{tabular}

Table 7: Portmanteau Q test of the residuals, category: 'Economics'

\begin{tabular}{cccccccc} 
No. & $\mathrm{H}$ & $\mathrm{I}$ & $\mathrm{K}$ & $\mathrm{L}$ & $\mathrm{M}$ & $\mathrm{N}$ & $\mathrm{O}$ \\
\hline 1 & 0.2983 & 0.2362 & 0.9552 & 0.9099 & 0.5187 & 0.2572 & 0.4963 \\
2 & $0.0108^{*}$ & 0.3214 & 0.9896 & 0.9607 & $0.0202^{*}$ & 0.7684 & 0.4946 \\
3 & 0.2438 & 0.3824 & 0.1569 & 0.9607 & 0.1575 & 0.5093 & 0.7823 \\
4 & 0.1317 & 0.324 & 0.9831 & 0.9432 & 0.5207 & 0.9385 & 0.6874 \\
5 & 0.2809 & 0.33 & 0.1493 & 0.9385 & 0.2021 & 0.2509 & 0.5207 \\
6 & 0.2505 & 0.1775 & 0.9748 & 0.932 & 0.3242 & 0.2165 & 0.6262 \\
7 & 0.1907 & 0.9513 & 0.9908 & 0.9308 & 0.3097 & 0.2468 & 0.5508 \\
8 & 0.2296 & 0.3096 & 0.871 & 0.9335 & 0.3017 & 0.4269 & 0.5119 \\
9 & 0.6047 & 0.7855 & 0.7109 & 0.9793 & 0.0607 & 0.562 & 0.5727 \\
10 & 0.2026 & 0.3059 & 0.8872 & 0.924 & 0.2345 & 0.6045 & 0.651 \\
11 & 0.0595 & 0.152 & 0.9455 & 0.9481 & 0.4035 & 0.2761 & 0.5723 \\
12 & 0.3568 & 0.3319 & 0.9675 & 0.8753 & 0.3105 & 0.2466 & 0.6015 \\
13 & 0.1469 & 0.4525 & 0.9593 & 0.9445 & 0.0602 & 0.4387 & 0.7223 \\
14 & 0.2542 & 0.3195 & 0.9958 & 0.9384 & 0.3089 & 0.2061 & 0.6464 \\
15 & 0.2386 & 0.2983 & 0.1554 & 0.9329 & 0.2814 & 0.2454 & 0.6195 \\
16 & 0.2139 & 0.3383 & 0.9778 & 0.9284 & 0.3174 & 0.2441 & 0.584 \\
\hline
\end{tabular}


Table 8: Johansen cointegration test, excluding indices Cointegration rank

\begin{tabular}{ccc}
\hline Variable & 'Business and Economics' & 'Economics'^ \\
\hline LNRINCOME & 0 & 0 \\
UN & 0 & 0 \\
LNINVEST & 0 & 0 \\
LNPROD & 0 & 0 \\
LNCPI & 0 & 0 \\
LNSP & 0 & 0 \\
LNBANKR & 0 & 0 \\
\hline ^excluding 'stagnation' due to estimation issues
\end{tabular}




\section{References}

Aftalion, A. (1913). Les crises périodiques de surproduction. Riviére, Paris.

Allsopp, C. J. (1971). Review - Is the Business Cycle Obsolete? Edited by M. Bronfenbrenner. The Economic Journal, 81(324):951-953.

Besomi, D. (2011). Naming crises: a note on semantics and chronology. In Besomi, D., editor, Crises and Cycles in Economic Dictionaries and Encyclopaedias, pages 54-132. Routledge, London.

Bronfenbrenner, M., editor (1969). Is the Business Cycle Obsolete? Wiley, New York.

Cardoso, A. R., Guimarães, P., and Zimmermann, K. F. (2010). Trends in economic research: An international perspective. Kyklos, 63(4):479-494.

Dal-Pont Legrand, M. and Hagemann, H. (2007). Business cycles in juglar and schumpeter. The History of Economic Thought, 49(1):1-18.

Diamond, A. M. (2009). Schumpeter vs. Keynes: 'in the long run, not all of us are dead'. Journal of the History of Economic Thought, 31(4):531-541.

Durbin, E. F. M. (1933). Purchasing Power and Trade Depression. A Critique of Under-consumption Theories. Jonathan Cape, London.

Elliott, G., Rothenberg, T. J., and Stock, J. H. (1996). Efficient Tests for an Autoregressive Unit Root. Econometrica, 64(4):813-36.

Fabian, A. (1989). Speculation on distress: the popular discourse of the panics of 1837 and 1857. Yale Journal of Criticism, 3(1):127-142.

Fisher, I. (1932). Booms and Depressions: Some First Principles. Adelphi, New York.

Fisher, I. (1933). The debt-deflation theory of great depressions. Econometrica, 1(4):337-357.

Garrett, T. A. (2007). The rise in personal bankruptcies: The eight federal reserve district and beyond. Federal Reserve Bank of St. Louis REVIEW, 89 (1):15-37.

Geiger, N. (2014). The rise of behavioural economics: A quantitative assessment. Paper presented at the 18th Annual ESHET Conference on "Liberalisms: perspectives and debates in the history of economic thought", 29-31 May 2014 in Lausanne. 
Granger, C. (1980). Testing for causality: A personal viewpoint. Journal of Economic Dynamics and Control, 2(0):329 - 352.

Granger, C. W. J. (1969). Investigating Causal Relations by Econometric Models and Cross-Spectral Methods. Econometrica, 37(3):424-38.

Hamilton, J. (1994). Time series analysis. Princeton Univ. Press, Princeton, NJ.

Hicks, J. R. (1950). A Contribution to the Theory of the Trade Cycle. Clarendon Press, Oxford.

Johansen, S. (1988). Statistical analysis of cointegration vectors. Journal of Economic Dynamics and Control, 12(2-3):231-254.

Johnson, H. G. (1971). The keynesian revolution and the monetarist counterrevolution. The American Economic Review, 61(2):1-14.

Keynes, J. M. (1936). The General Theory of Employment, Interest, and Money, volume VII of The Collected Writings of John Maynard Keynes. Macmillan, London (1973).

Kim, E. H., Morse, A., and Zingales, L. (2006). What has mattered to economics since 1970. The Journal of Economic Perspectives, 20(4):189-202.

Kurz, H. D. (2006). Whither the history of economic thought? going nowhere rather slowly? The European Journal of the History of Economic Thought, $13(4): 463-488$.

Laibson, D. and Zeckhauser, R. (1998). Amos tversky and the ascent of behavioral economics. Journal of Risk and Uncertainty, 16(1):7-47.

Ljung, G. M. and Box, G. E. P. (1978). On a measure of lack of fit in time series models. Biometrika, 65(2):297-303.

Lucas, R. E. (2003). Macroeconomic priorities. The American Economic Review, $93(1): 1-14$.

Mills, J. (1868). On credit cycles and the origin of commercial panics. In Transactions of the Manchester Statistical Society, pages 11-40. J. Roberts, Manchester.

Mitchell, W. C. (1913). Business Cycles. University of California Press, Berkeley.

Neumark, F. (1975). Zyklen in der Geschichte ökonomischer Ideen. Kyklos, 28(2):257-285. 
Nielsen, B. (2001). Order determination in general vector autoregressions. Economics Papers 2001-W10, Economics Group, Nuffield College, University of Oxford.

Officer, L. H. and Williamson, S. H. (2015). The annual consumer price index for the united states, 1774-2014.

Petris, G. (2010). An R package for dynamic linear models. Journal of Statistical Software, 36(12):1-16.

Petris, G., Petrone, S., and Campagnoli, P. (2009). Dynamic Linear Models with $R$. Use R! Springer.

Richter, F. E. (1923). Recent Books on Business Cycles. The Quarterly Journal of Economics, 38(1):153-168.

Romer, C. D. (1999). Changes in business cycles: Evidence and explanations. The Journal of Economic Perspectives, 13(2):23-44.

Schumpeter, J. A. (1931). The theory of the business cycle. Keizaigaku Ronshu The Journal of Economics, 4:1-18.

Shackle, G. L. S. (1967). The Years of High Theory: Invention and Tradition in Economic Thought 1926-1939. Cambridge University Press, Cambridge.

Shiller, R. J. (2015). Irrational Exuberance. Princeton: Princeton University Press.

Skidelsky, R. (2009). Keynes: The Return of the Master. Allen Lane, London.

Soo, C. K. (2013). Quantifying animal spirits: News media and sentiment in the housing market. Ross School of Business Paper No. 1200.

Walsh, C. E. (1999). Changes in the Business Cycle. FRBSF Economic Letter, 1999(16). 


\section{SCHRIFTENREIHE DES \\ PROMOTIONSSCHWERPUNKTS \\ GLOBALISIERUNG UND BESCHÄFTIGUNG}

Nr. 1/1998 Bernhard Holwegler und Hans-Michael Trautwein, Beschäftigungswirkungen der Internationalisierung, eine Studie aus- und einfließender Direktinvestitionen der Metall- und Elektroindustrie im Raum Stuttgart

Nr. 2/1998 Heinz-Peter Spahn, Heterogeneous Labour, the Unemployment Equilibrium, and the Natural Rate

Nr. 3/1998 Philip Arestis, Iris Biefang-Frisancho Mariscal and Harald Hagemann, Capital Shortage Unemployment in Germany and the UK

Nr. 4/1999 Theo Schewe, Full Employment in the Age of Globalisation? PoliticalEconomic Analysis of Effective Employment Policies in the Nineties. The Case of Norway.

Nr. 5/1999 Hagen Krämer, Dienstleistungen: Motor für Wachstum und Beschäftigung in Deutschland?

Nr. 6/1999 Jürgen Kromphardt, Lohnbildung und Beschäftigung

Nr. 7/1999 Ewald Walterskirchen, Beschäftigungspolitik in Österreich

Nr. 8/1999 Reiner Franke, Lohnzurückhaltung, Beschäftigung und (zu) einfache empirische Zusammenhänge

Nr. 9/1999 Peter Kalmbach, Implications of Integration for Wage Formation and Employment

Nr. 10/2000 Arne Heise, Theoretische Grundlagen einer Verhaltensabstimmung der makroökonomischen Politikträger

Nr. 11/2000 Eckhard Hein und Carsten Ochsen, Monetary Interest Rates, Income Shares, and Investment: Theory and Empirical Evidence for France, Germany, the UK, and the USA

Nr. 12/2000 Guntram R. M. Hepperle, Airbus - ein gelungenes Beispiel für beschäftigungsorientierte Industriepolitik?

Nr. 13/2000 Bernhard Holwegler, Implikationen der Technologiediffusion für technologische Arbeitslosigkeit

Nr. 14/2000 Markus Schreyer, Wachstum und Beschäftigung vor dem Hintergrund des Solowschen Produktivitätsparadoxons

Nr. 15/2000 Mauro Boianovsky, Some Cambridge Reactions to The General Theory: David Champernowne and Joan Robinson on Full Employment

Nr. 16/2001 Marc-Peter Radke, Law and Economics of Microsoft vs. U.S. Department of Justice: A New Economic Paradigm for Antitrust in Network Markets or Inefficient Lock-in of Antitrust Policy?

Nr. 17/2001 Daniel Hartmann, Taylor-Regel und amerikanische Geldpolitik 
Nr. 18/2002

Nr. 19/2002

Nr. 20/2004

Nr. 21/2004

Nr. $22 / 2005$

Nr. 23/2006

Nr. $24 / 2007$

Nr. $25 / 2007$

Nr. $26 / 2008$

Nr. 27/2009

Nr. $28 / 2009$

Nr. 29/2009

Nr. 30/2009

Nr. 31/2010

Nr. 32/2010

Nr. 33/2011

Nr. 34/2011

Nr. 35/2011

Nr. 36/2012

Nr. 37/2012

Nr. 38/2012
Jutta Maute, Stabilization via Currency Board

Daniel Hartmann, The Fed Strategy: Successful but Out-of-Date?

Dirk H. Ehnts, Spatial Decisions of Multinational Enterprises and their Effect on Local Firms

Theo Schewe, Makroökonomische Probleme des extensiven Rohstoffexports in einer entwickelten Volkswirtschaft - analysiert am Beispiel der norwegischen Erdölwirtschaft

Georg Erber \& Aida Sayed-Ahmed, Offshore Outsourcing - A global shift in the present IT industry

Deborah Schöller, Service Offshoring: A Challenge for Employment? Evidence from Germany

Ralf Rukwid, Arbeitslosigkeit und Lohnspreizung - Empirische Befunde zur Arbeitsmarktsituation gering Qualifizierter in Deutschland

Julian P. Christ, Varieties of Systems of Innovation: A Survey of their Evolution in Growth Theory and Economic Geography

Andreja Benković \& Juan Felipe Mejía, Tourism as a Driver of Economic Development: The Colombian Experience

Julian P. Christ \& André P. Slowak, Standard-Setting and Knowledge Dynamics in Innovation Clusters

Constanze Dobler, The Impact of Institutions, Culture, and Religion on Per Capita Income

Julian P. Christ \& André P. Slowak, Why Blu-ray vs. HD-DVD is not VHS vs. Betamax: The Co-evolution of Standard-setting Consortia

Patricia Hofmann, Die nеме nеuе Außenhandelstheorie: das Melitz-Modell

Julian P. Christ, The Geography and Co-location of EuropeanTechnologyspecific Co-inventorship Networks

Julian P. Christ, Geographic Concentration and Spatial Inequality: Two Decades of EPO Patenting at the Level of European Micro Regions

Finn Marten Körner, An Equilibrium Model of 'Global Imbalances' Revisited

Constanze Dobler \& Harald Hagemann, Economic Growth in the Post-Socialist Russian Federation after 1991: The Role of Institutions

Constanze Dobler, Instability, Economic Stagnation and the Role of Islam in the North Caucasus

Georg Erber und Harald Hagemann, Wachstums- und Investitionsdynamik in Deutschland

Ralf Rukwid, Grenzen der Bildungsexpansion? Ausbildungsinadäquate Beschäftigung von Ausbildungs- und Hochschulabsolventen in Deutschland Vadim Kufenko, Empirical Analysis of Regional Economic Performance in Russia: Human Capital Perspective 
Nr. 39/2013 Harald Hagemann und Vadim Kufenko, The Political Kuznets Curve for Russia: Income Inequality, Rent Seeking Regional Elites and Empirical Determinants of Protests during 2011/2012

Nr. 40/2014 Danila Raskov und Vadim Kufenko, The Role of Old Believers' Enterprises: Evidence from the Nineteenth Century Moscow Textile Industry

Nr. 41/2014 Harald Hagemann, Georg Erber, Niels Geiger, Johannes Schwarzer und Oliver Zwiessler, Wachstums- und Investitionsdynamik in Deutschland

Nr. 42/2015 Vincent Geloso und Vadim Kufenko, Malthusian Pressures: Empirical Evidence from a Frontier Economy

Nr. 43/2015 Christine Clement, The Formal-Informal Economy Dualism in a Retrospective of Economic Thought since the 1940s

Nr. 44/2015 Niels Geiger, The Rise of Behavioural Economics: A Quantitative Assessment

Nr. 45/2015 Vadim Kufenko und Niels Geiger, Stylized Facts of the Business Cycle: Universal Phenomenon, or Institutionally Determined?

Nr. 46/2015 Niels Geiger und Vadim Kufenko, Business Cycles in the Economy and in Economics: An Econometric Analysis 
Die Ursachen der gegenwärtig hohen Arbeitslosigkeit in einigen europäischen Ländern sind nicht allein in 'Funktionsproblemen des Arbeitsmarktes' zu suchen, sondern auch in Nachfrage- und Angebotsentwicklungen auf Güter- und Finanzmärkten. Im Promotionsschwerpunkt Globalisierung und Beschäftigung werden daher Dissertationsvorhaben gefördert, in denen die Beschäftigungseffekte gesamtwirtschaftlicher Entwicklungen untersucht werden - beispielsweise von neuen Technologien, von Prozessen der Internationalisierung und Systemtransformation, von marktseitigen Finanzierungsbeschränkungen oder von unterschiedlichen Strategien der Fiskal-, Geld- und Währungspolitik.

Die Betreuung und Vernetzung der Arbeiten im Promotionsschwerpunkt entspricht der Arbeitsweise eines Graduiertenkollegs. Betreuer des Schwerpunkts und Herausgeber der Schriftenreihe sind folgende Hochschullehrer:

Prof. Dr. Harald Hagemann

Institut für Volkswirtschaftslehre $(520 \mathrm{H})$

Universität Hohenheim

D-70593 Stuttgart

Prof. Dr. Heinz-Peter Spahn

Institut für Volkswirtschaftslehre (520A)

Universität Hohenheim

D-70593 Stuttgart

Prof. Dr. Hans-Michael Trautwein

Fakultät II - Institut für Volkswirtschaftslehre

Carl von Ossietzky Universität

D-26111 Oldenburg harald.hagemann@uni-hohenheim.de

peter.spahn@uni-hohenheim.de

michael.trautwein@uni-oldenburg.de

Dissertationsprojekte im Schwerpunkt können durch Promotionsstipendien des Evangelischen Studienwerks e.V. Villigst gefördert werden. Bewerbungsunterlagen können unter folgender Adresse angefordert werden:

Evangelisches Studienwerk e.V.

Promotionsförderung

Iserlohner Str. 25

58239 Schwerte

Tel.: 02304/755-215, Fax: 02304/755-250

Weitere Informationen zum Promotionsschwerpunkt sowie die Diskussionsbeiträge der Violetten Reihe im PDF-Format finden sich im Internet unter der Adresse:

http://www.globalization-and-employment.de 